\title{
Association of Levels of Anxiety in Resident Doctors with Factors related to the Postgraduate Training in Teaching Hospitals
}

\author{
Sehrish Zehra, Syed Muhammad Zulfiqar Hyder Naqvi, Muhammad Zafar Iqbal Hydrie, Samira Faiz,
} Farhan Muhammad Qureshi, Syed Imtiaz Ahmed Jafry

ABSTRACT:

Objective: To assess level of anxiety, its associated factors and coping strategies in postgraduate trainees of public and private teaching hospitals of Karachi

Study Design and Setting: It was a cross-sectional study. The data was collected from different major teaching hospitals February 2019 till April

Methodology: A total of 230 postgraduate trainees were interviewed using a pre-tested structured questionnaire specifically designed for this study which included General Anxiety Disorder-7 Scale and Brief COPE Questionnaire. Data were analyzed on SPSS version 21. Chi-square test and multinomial logistic regression was performed and P-value $<0.05$ was considered as statistically significant

Results: Total $39.6 \%$ of the participants had no anxiety, $34.3 \%$ had mild, $16.1 \%$ had moderate while $10.0 \%$ had severe anxiety. Being single, nuclear family system and low monthly household income had higher odds of having severe anxiety (Adjusted Odds Ratio (AOR); 5.50, 95\% CI 1.38,22.14, AOR; 2.50, 95\% CI 0.83,7.51 and AOR; 3.17, 95\% CI 0.96,10.49 respectively). Severe anxiety was also highly associated with irregular sleep pattern (AOR; 2.06, 95\% CI 0.70, 6.06), no daily exercise (AOR; 5.01, 95\% CI 1.21, 2.69) and lack of job satisfaction (AOR; 2.64, 95\% CI 0.90, 7.90). The most frequently adapted coping strategies by participants who were found to have anxiety were, planning (89.9\%), acceptance $(87 \%)$ and religion $(85.6 \%)$.

Conclusion: Postgraduate trainees should be provided with psychological counseling and support at workplace to keep them mentally healthy to enhance their everyday performance in dealing and treating patients.

Keywords: Anxiety levels, Coping Strategies, Medical residents, Postgraduate trainees, Teaching hospitals.

- - - - - - - - - - - - - - - - - - - - - - - - - - - -

Zahra S, Naqvi SMZH, Hydrie MZI, Faiz S, Qureshi FM, Jafry SIA. Association of Levels of Anxiety in Resident Doctors with Factors related to the Postgraduate Training in Teaching Hospitals. J Bahria Uni Med Dental Coll. 2022; 12(1):19-24 DOI: https://doi.org /10.51985/JBUMDC2021078

This is an Open Access article distributed under the terms of the Creative Commons Attribution Non Commercial License (http:// creativecommons/org/licences/by-nc/4.0) which permits unrestricted non commercial use, distribution and reproduction in any medium, provided the original work is properly cited.

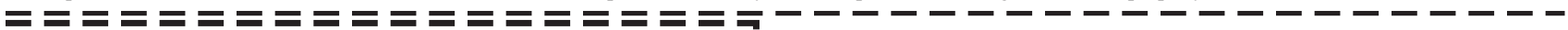

I Sehrish Zehra

I Senior Lecturer, Department of Community Health Sciences

Karachi Institute of Medical Sciences (KIMS), Karachi

Email: Syeda.zehra57@gmail.com

I

Syed Muhammad Zulfiqar Hyder Naqvi

Assistant Professor, Department of Community Health Sciences

I Baqai Medical University, Karachi

Email: dr.smzhnaqvi@gmail.com

I Muhammad Zafar Iqbal Hydrie

Associate Professor, Department of Community Health Sciences

Baqai Institute of Health Sciences, Baqai Medical University, I Karachi

I Email: zafarhydrie@gmail.com

I Samira Faiz

Assistant Professor, Department of Community Health Sciences

Karachi Institute of Medical Sciences (KIMS), Karachi

I Email: samirafaiz@ymail.com

I Farhan Muhammad Qureshi

I Assistant Professor, Department of Community Health Sciences

Karachi Institute of Medical Sciences (KIMS), Karachi

I Email: drfarhanqureshi@hotmail.com

Syed Imtiaz Ahmed Jafry

I Syed Imtiaz Ahmed Jafry
Associate Professor, Department of Community Health

I Sciences

Baqai Medical University, Karachi

Email: Imtiaz8842@gmail.com

Received: 04-Oct-2021

Accepted: 25-Nov-2021

Heceled. 25-Nov-2021

\section{INTRODUCTION:}

The field of medicine is very tense and demanding profession involving a variety of stressors and risks. ${ }^{1}$ Severe stress level in health care workers has found to be not only harmful to their own health but is reported to be detrimental to the health of the patients and to the subordinates and colleagues as well. ${ }^{1}$ These stressors can lead to reduced concentration and self-esteem, compromised decision making and increased level of anxiety. ${ }^{2}$ It is considered that the level of training is the only stressor among doctors but, socio-demographic factors and working environment of the hospital also plays a key role. ${ }^{2}$ Not addressed timely, the increased level of anxiety manifests in the form of severe psychological and behavioural issues or even more serious issues like depression which is the fourth leading cause of disability world-wide ${ }^{3}$ and suicide in worst cases. ${ }^{1,2}$ In a New York medical university-based survey, the prevalence of anxiety was eight times higher among medical trainees than their age matched controls causing a significant effect on their academic and clinical performance. ${ }^{3}$ Long working duration, female gender, low income group, peer pressure, job dissatisfaction and marriage are some common risk factors found to be the leading causes of anxiety. ${ }^{4,5}$ Doctors start facing psychological distress right from the beginning of their medical school 
Association of Levels of Anxiety in Resident Doctors with Factors related to the Postgraduate Training in Teaching Hospitals

which continues throughout their training and later professional life. ${ }^{3}$ It may not only affect their personal life in the form of sceptical behaviour and emotional exhaustion but may also affect their patient care performance as well. ${ }^{6}$

Coping refers to the opinions, views and actions of an individual to deal with stressful life events ${ }^{7}$ Every person responds to anxiety by adapting and using different coping strategies which may include acceptance, self-blame, planning, positive reframing, religious practices, isolation and sleeping etc. ${ }^{8,9}$ However, resilience may develop with time seeking different strategies that might be adapted spontaneously or may be self-directed. ${ }^{7}$ Usually, it has been noticed that health care workers are adapted toward selfdistraction in which they draw their own thoughts away from stressors. ${ }^{8}$ However, the coping strategies may vary deemed to the individual thoughts and circumstances. ${ }^{9}$

Anxiety may lead to depression which can be prevented by addressing anxiety early in time and in an appropriate way.

${ }^{1-3}$ Several studies have explored the presence of stress and depression among postgraduate trainees internationally ${ }^{1,2}$ and even in Pakistan. ${ }^{10}$ However, the local data on prevalence of anxiety and various coping mechanisms is scarce. The main objective of our study was to find out the prevalence of general anxiety disorder among post graduate trainees to carryout in time preventive measures. Secondly, to explore the potential risk factors that may lead to anxiety. Moreover, it was intended to identify various coping strategies that the postgraduate trainees opt to deal with the continuous and yet deteriorating mental ailment to keep themselves going with everyday challenges.

\section{METHODOLOGY:}

To study the prevalence of anxiety among post graduate trainees, data were collected through convenient sampling from different major teaching hospitals of Karachi from February 2019 till April 2019. The study was approved by the Ethical Review Board and the Institutional Review Board Baqai Medical University. An online software was used to calculate the sample size. The prevalence of anxiety was taken as $16 \%,{ }^{3}$ and $5 \%$ absolute precision the sample size was calculated to be 207 with $95 \%$ confidence level that was inflated to 230. After a written informed consent, 280 participants were interviewed. Irrespective of age and gender, all the volunteered participants were included who were working as Post-graduate trainees. However, participants were inquired about history of any diagnosed medical, surgical or psychological diseases or disorder through selfreport. Those found positive, were excluded. Similarly, self -reporting pregnant female participants were also excluded. To rule out undiagnosed depression, a depression screening tool PHQ-2 (Patient Health Questionnaire-2) ${ }^{11}$ was used after which we had a morbidity, pregnancy and depression free sample of 230 participants - eligible to participate in the study.
The basic socio-demographic traits like age, gender, marital status, family system, monthly income and other factors that are known or might be associated ${ }^{2}$ with anxiety among health care providers were recorded. These include, job satisfaction, peer pressure, sleep duration, regular physical exercise or walk, history of any tragic event and other job or private practice despite of the training. The level of anxiety was assessed through "General Anxiety Disorder-7 Scale (GAD-7)" 12 while the "Brief COPE questionnaire" 7 was used to observe the coping strategies opt by the respondents who were suffering from anxiety.

GAD-7 Anxiety Scale: It is a seven-item scale to assess level of anxiety. Having the response categories of not at all, several days, more than half the days, and nearly every day which can be calculated by assigning scores of $0,1,2$, and 3, respectively. Total score of the seven items ranges from 0 to 21. Scores ranging from 0-4, 5-9, 10-14 and 1521 represent cut points for no anxiety, mild, moderate, and severe anxiety, respectively.

Brief COPE Questionnaire: Brief COPE is related to assessment of 14 different coping strategies namely, selfdistraction, active coping, denial, substance use, use of emotional support, use of instrumental support, behavioral disengagement, venting, positive reframing, planning, humor, acceptance, religion and self-blame. Consisting of 28 questions ( 2 questions per type), the responses are measured on a 4-point Likert-type scale from 1 being 'I've not done this at all' till 4 being 'I've been doing this a lot'. Only those participants who were found to have anxiety by GAD-7 were given the Brief COPE Questionnaire to observe the coping strategies.

Data were analyzed by SPSS version 21.0 whereas graphical presentations were made using MS Excel. Frequencies and percentages were used to present the descriptive analysis. Categorical data was analyzed using chi-square test with 0.05 significance level. To compare continuous data, t-tests and Analysis of Variance (ANOVA) were used. Logistic regression model was used to analyze the categorical Anxiety Score.

\section{RESULTS:}

A total of 230 participants were included in the study with the mean age of residents was $28.44 \pm 2.43$ years and all the participants belonged to the religion Islam. Table 1 shows the descriptive findings of the factors potentially leading to anxiety and their comparison with the level of anxiety taken as no anxiety, mild, moderate and severe. Gender ( $\mathrm{p}=$ $0.006)$, monthly income $(\mathrm{p}=0.021)$, peer pressure $(\mathrm{p}<$ $0.001)$, history of tragic incident $(\mathrm{p}<0.001)$, having regular exercise or walk $(\mathrm{p}=0.005)$ and job satisfaction $(\mathrm{p}=0.011)$ were found to be highly statistically significant with levels of anxiety.

The association of factors leading to anxiety and different level of anxiety based on logistic regression model is shown 
Sehrish Zehra, Syed Muhammad Zulfiqar Hyder Naqvi, Muhammad Zafar Iqbal Hydrie, Samira Faiz, Farhan Muhammad Qureshi et.al

in table 2. Values present adjusted odds ratios with corresponding $95 \%$ confidence intervals. Age group younger than 30 years were observed to have mild anxiety than the older age group (AOR 1.28; 95\% CI 0.61, 2.66). On the other hand, being male was found to be protective towards developing anxiety. With the odds of 5.50 (95\% CI 1.34, 22.14) and 2.655 (95\% CI 0.97, 7.23) single participants were likely to have severe and moderate anxiety respectively. Less household income was also found to be highly associated with severe anxiety (AOR 3.17; 95\% CI 0.96,10.49). Participants who were not regular with daily physical exercise had 5 times more chance to develop anxiety than those who exercise regularly. Similarly, lack of job satisfaction was highly associated with severe anxiety (AOR 2.64; 95\% CI $0.90,7.90)$.

Participants scoring high on GAD -7 Scale were asked about different approaches they usually opt to deal with anxiety. The various strategies used to cope with anxiety is shown in figure 1 . The most frequently being planning $(89.9 \%)$ and acceptance $(87.1 \%)$, whereas the least adopted was substance use $(7.9 \%)$.

The pie chart illustration in figure 2 displays the overall prevalence of anxiety level among participants with $39.6 \%$ of the participants not having any symptoms of anxiety, $34.3 \%$ mild, $16.1 \%$ moderate while $10.0 \%$ had severe anxiety.

\section{DISCUSSION:}

In the current era of research and development, there has been a surge to get deep insight into the physical, mental and psychological wellbeing of health care personnel. Reason being the increased prevalence of physical and mental health issues among the health care workers. ${ }^{1}$ There is a general assumption that doctors and health care workers are trained to adopt the pressure and stress of their profession and do not need any support. ${ }^{1,13}$ However, working in stressful and critical environment, health care professionals are among the most vulnerable occupational categories. ${ }^{14}$ Supporting the literature, our study observed that $60.4 \%$ of the postgraduate trainees were found to be suffering from some level of anxiety. According to our results, $10 \%$ of the participants were having severe, $16 \%$ moderate while $34.3 \%$ were having only mild anxiety. Dave et al. in 2018, found $36.58 \%$ anxiety among resident doctors that is almost half of our findings. Nevertheless, the residents had some level of depression $(27.7 \%)$ and stress $(24.2 \%)$ as well. ${ }^{2}$ Our finding was consistent to some extent with another study by in 2020 by Khurshid et al. They compared the frequency of anxiety among consultants and postgraduate trainees and observed that $48 \%$ of the postgraduate trainees were suffering from anxiety that significantly differed with the prevalence of anxiety among consultants that was found to be $20 \%{ }^{10}$.

Table 1: Potential risk factors with different Level of Anxiety among participants $(\mathrm{N}=230)$

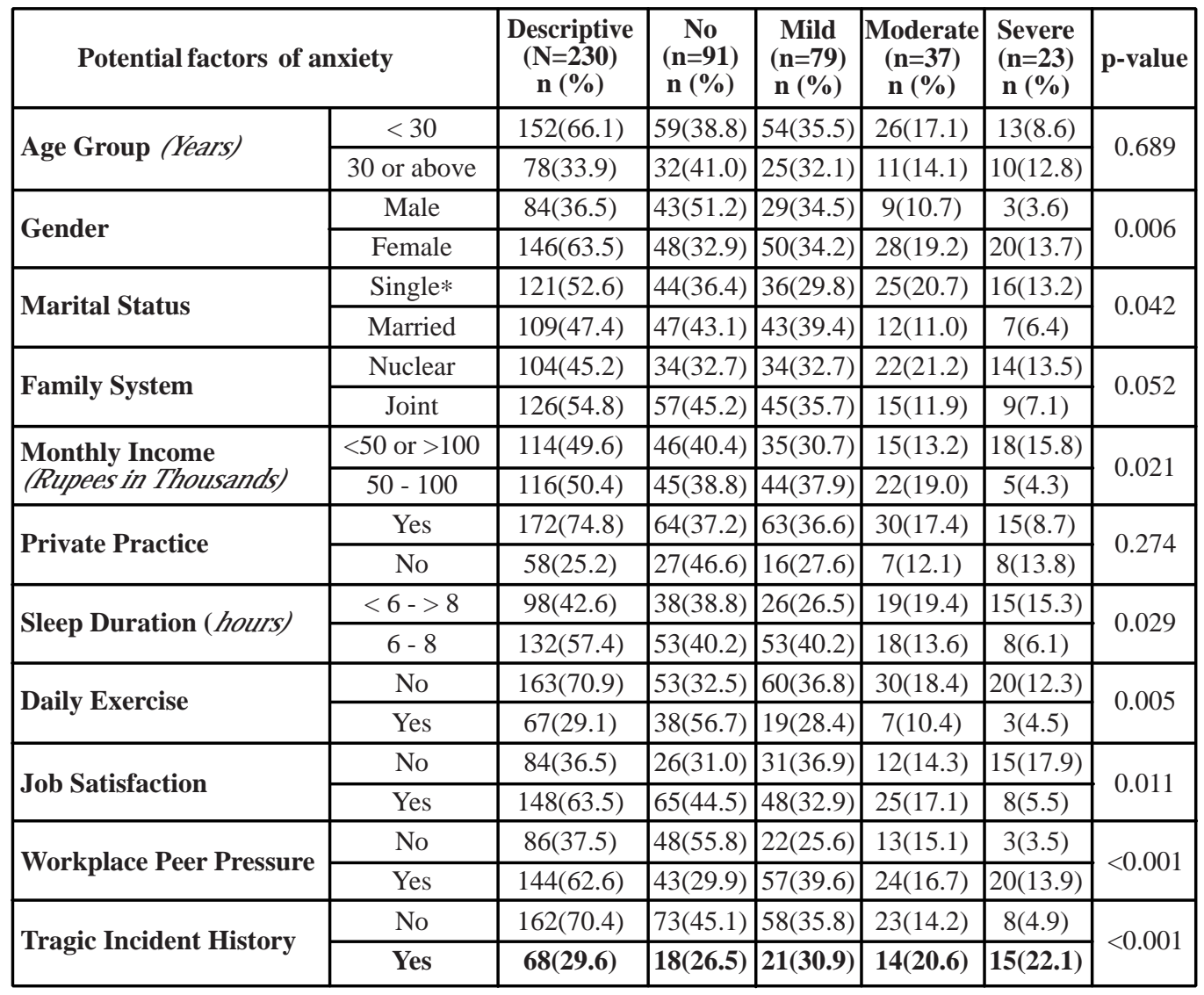


Association of Levels of Anxiety in Resident Doctors with Factors related to the Postgraduate Training in Teaching Hospitals

Table 2: Logistic Regression Analysis of Anxiety Levels with its Potential Risk Factors

\begin{tabular}{|c|c|c|c|c|c|c|}
\hline \multirow{2}{*}{$\begin{array}{l}\text { Potential Factors } \\
\text { of Anxiety }\end{array}$} & \multicolumn{2}{|c|}{ Mild Anxiety } & \multicolumn{2}{|c|}{ Moderate Anxiety } & \multicolumn{2}{|c|}{ Severe Anxiety } \\
\hline & $\underset{\left(95 \% \mathbf{C I}^{+}\right)}{\mathbf{A O R}^{*}}$ & $p$ value & $\underset{\left(\mathbf{9 5 \%} \% \mathbf{C I}^{+}\right)}{\mathbf{A O R}^{*}}$ & $p$ value & $\underset{\left(95 \% \mathbf{C I}^{\frac{1}{4}}\right)}{\mathbf{A O R}^{*}}$ & $p$ value \\
\hline $\begin{array}{l}\text { Age Group; } \\
<30 \text { years }\end{array}$ & $\begin{array}{c}1.28 \\
(0.61,2.66)\end{array}$ & 0.517 & $\begin{array}{c}0.69 \\
(0.25,1.94)\end{array}$ & 0.491 & $\begin{array}{c}0.19 \\
(0.05,0.74)\end{array}$ & 0.017 \\
\hline $\begin{array}{l}\text { Gender; } \\
\text { Male }\end{array}$ & $\begin{array}{c}0.66 \\
(0.34,1.26) \\
\end{array}$ & 0.216 & $\begin{array}{c}0.30 \\
(0.12,0.77) \\
\end{array}$ & 0.012 & $\begin{array}{c}0.12 \\
(0.03,0.53) \\
\end{array}$ & 0.005 \\
\hline $\begin{array}{l}\text { Marital Status; } \\
\text { Single }\end{array}$ & $\begin{array}{c}0.82 \\
(0.40,1.65) \\
\end{array}$ & 0.581 & $\begin{array}{c}2.65 \\
(0.97,7.23) \\
\end{array}$ & 0.056 & $\begin{array}{c}5.50 \\
(1.34,22.14) \\
\end{array}$ & 0.018 \\
\hline $\begin{array}{l}\text { Family System; } \\
\text { Nuclear }\end{array}$ & $\begin{array}{c}1.20 \\
(0.62,2.33)\end{array}$ & 0.58 & $\begin{array}{c}1.86 \\
(0.79,4.37)\end{array}$ & 0.153 & $\begin{array}{c}2.50 \\
(0.83,7.51)\end{array}$ & 0.102 \\
\hline $\begin{array}{l}\text { Monthly Income; } \\
<50 \text { \& > } 100 \text { Thousand }\end{array}$ & $\begin{array}{c}0.8 \\
(0.42,1.50)\end{array}$ & 0.487 & $\begin{array}{c}0.57 \\
(0.24,1.32)\end{array}$ & 0.192 & $\begin{array}{c}3.17 \\
(0.96,10.49)\end{array}$ & 0.059 \\
\hline $\begin{array}{l}\text { Private Practice; } \\
\text { No }\end{array}$ & $\begin{array}{c}1.38 \\
(0.65,2.96)\end{array}$ & 0.396 & $\begin{array}{c}1.72 \\
(0.64,4.59)\end{array}$ & 0.274 & $\begin{array}{c}0.66 \\
(0.21,2.08)\end{array}$ & 0.486 \\
\hline $\begin{array}{l}\text { Sleep Duration; } \\
<6 \text { or }>8 \text { hours }\end{array}$ & $\begin{array}{c}0.59 \\
(0.30,1.17)\end{array}$ & 0.133 & $\begin{array}{c}1.49 \\
(0.66,3.37)\end{array}$ & 0.335 & $\begin{array}{c}2.06 \\
(0.70,6.06)\end{array}$ & 0.189 \\
\hline $\begin{array}{l}\text { Daily Exercise; } \\
\text { No }\end{array}$ & $\begin{array}{c}1.98 \\
(0.98,3.97)\end{array}$ & 0.054 & $\begin{array}{c}2.91 \\
(1.12,7.55)\end{array}$ & 0.028 & $\begin{array}{c}5.01 \\
(1.21,20.69)\end{array}$ & 0.026 \\
\hline $\begin{array}{l}\text { Job Satisfaction; } \\
\text { No }\end{array}$ & $\begin{array}{c}1.26 \\
(0.62,2.56)\end{array}$ & 0.516 & $\begin{array}{c}0.79 \\
(0.32,1.93)\end{array}$ & 0.608 & $\begin{array}{c}2.64 \\
(0.90,7.90)\end{array}$ & 0.082 \\
\hline $\begin{array}{l}\text { Peer Pressure at Work; } \\
\text { No }\end{array}$ & $\begin{array}{c}0.37 \\
(0.19,0.74)\end{array}$ & 0.005 & $\begin{array}{c}0.57 \\
(0.25,1.32)\end{array}$ & 0.194 & $\begin{array}{c}0.20 \\
(0.05,0.82)\end{array}$ & 0.025 \\
\hline $\begin{array}{l}\text { Tragic Incident History; } \\
\text { No }\end{array}$ & $\begin{array}{c}0.8 \\
(0.37,1.72)\end{array}$ & 0.57 & $\begin{array}{c}0.41 \\
(0.17,0.99)\end{array}$ & 0.049 & $\begin{array}{c}0.14 \\
(0.05,0.44)\end{array}$ & 0.001 \\
\hline
\end{tabular}

CI, Confidence intervals, *AOR, Adjusted odds ratio

Figure1: Anxiety coping strategies in percentages:

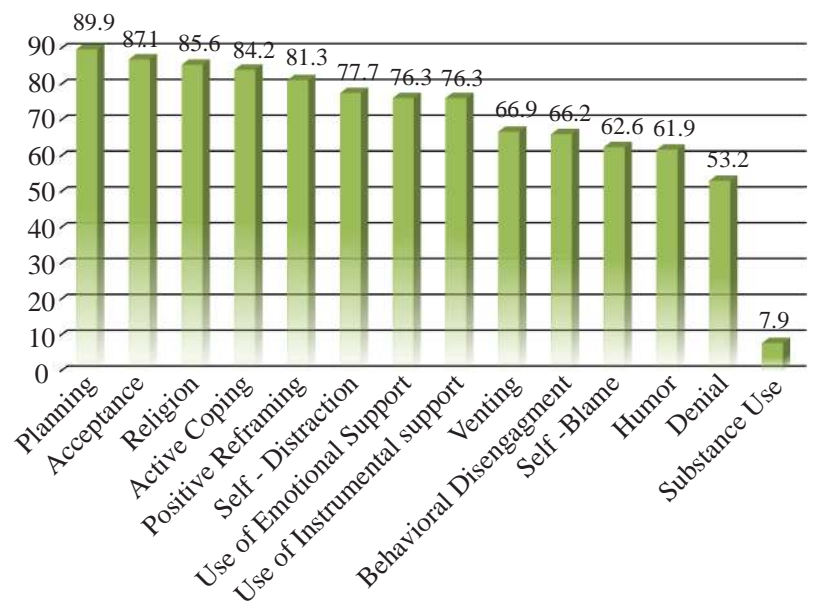

Yet, Mousa et al., in 2016 reported that only $15.9 \%$ of the postgraduate residents were dealing with the misery of anxiety which was much less than our findings. ${ }^{3}$ These variations in study findings may be attributed to several factors deemed to gender, working environment, peer pressure, job satisfaction, ergonomics, management-employee relationship, seasonal workload and so on. Some of the
Figure 2: Over all anxiety level among participants

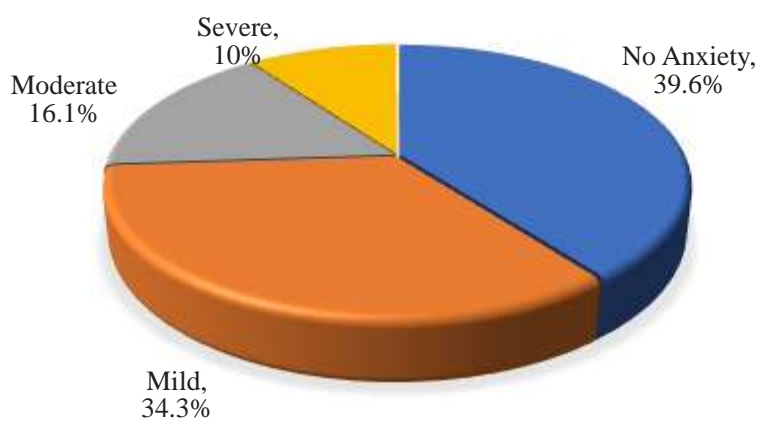

leading factors were clutched in this study to find out the relationship with different levels of anxiety.

We observed that female postgraduates were more likely to have moderate and severe anxiety. It is also evident from literature that females suffer more with anxiety than males. ${ }^{15,16}$ Studies also show that even female medical students had more anxiety than male students. ${ }^{17}$ The higher number of females may explain the high prevalence of anxiety in this study as we had more than $60 \%$ female participants. Many previous studies showed low frequency of anxiety 
i.e., $22 \%$ and $36.58 \%$ most likely as the female respondents were lesser in number i.e., $25 \%$ and $45.6 \%$ respectively. ${ }^{1,}$ ${ }^{2}$ Therefore, it is evident that gender has an immense impact on the overall result.

Low monthly household income leads to a cascade of reactions including, limited resources, sub-standard lifestyle and poor physical and mental health, making a person at risk for anxiety. Poor socio-economic status and fiscal problems increase the odds of having anxiety. ${ }^{16}$ We found that participants with low or very high monthly household income were more likely to have severe anxiety, though we had more participants with high-income as compared to low, but no data supports that high income may lead to anxiety. Nonetheless, continuous inflation and lifestyle upgradation might be the causative factors that needs to be addressed in future studies.

The odds of having severe anxiety was 5 times and of having moderate was 2.6 times higher among the participants who were single. These findings are parallel to previous studies. 17,18 Though, there is some literature available that shows that anxiety was more prevalent among the married respondents as they have family responsibilities. ${ }^{19,20}$

Regular physical activity and adequate sleep are protective against anxiety and other physical and mental health issues.

${ }^{21}$ Having unhealthy lifestyle, improper sleep pattern and lack of daily physical activity is correlated with anxiety. ${ }^{16}$ Our study findings also support the data that participants who did not exercise or walk daily were more likely to have moderate and severe anxiety than participants who were regular at it. Regular exercise or walk keeps a person healthy leading to a healthy mind and less time for negative thoughts eventually making him less prone to anxiety. ${ }^{21}$

It was observed that anxiety was associated with peer pressure and lack of job satisfaction at the workplace. Moreover, participants with a history of tragic incident were more likely to develop anxiety. Similarly, Fan et al. reported that $40.5 \%$ of the participants had anxiety after an earthquake disaster. ${ }^{22}$ Negative life experiences and tragedies make individuals more vulnerable to develop anxiety that significantly affects the mental and physical health eventually making them unable to concentrate on work. ${ }^{23}$

Despite of stressful conditions at the workplace doctors develop some level of resilience to keep going. For this purpose, they usually adopt certain strategies to cope up. Mc Cain et al. in 2018 found self-blame, behavioral engagement and substance abuse, the most prevailing approaches among doctors. ${ }^{9}$ Furthermore, in 2020, Babore et al. concluded that positive reframing was a defensive feature against anxiety. ${ }^{14}$ Positive framing was found in the fifth place with $81.3 \%$ of respondents using it as a coping tool. By virtue of positive reframing, individuals improvise a difficult and negative situation positively performing as a better psychological wellbeing. ${ }^{24}$ Contradicting the above, we concluded that planning, acceptance and religion were the most frequent coping strategies among our study respondents while, substance abuse and denial were least used. Yet, several studies had observed that smoking, alcohol use and substance abuse were the commonest lines to deal with anxiety and demanding circumstances. ${ }^{3,16}$

Despite of adding job satisfaction as a proxy, which is a limitation of study, working atmosphere, employeemanagement relationship, job security and ergonomics, might be some of the causative factors of anxiety that should be addressed in future studies. Secondly, another limitation might be the greater number of female participants that may have affected the overall result to some extent. Efforts are needed to abstain them from the risk factors leading to anxiety including making duty schedule of postgraduate trainees in a less stressful way so that they have enough sleep and adequate time for themselves and their family. Incentives and supportive working environment in addition to regular psychological counseling and support can help them maintain good health.

\section{CONCLUSION:}

The study findings revealed that more than a quarter of the postgraduate trainees were found to have either moderate or severe anxiety.

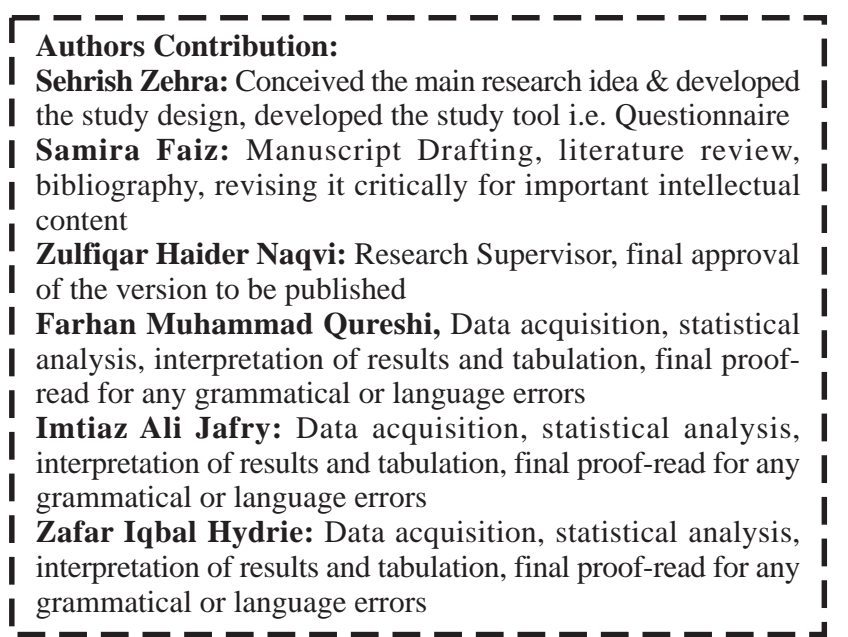

\section{REFERENCES:}

1. Sadiq MS, Morshed NM, Rahman W, Chowdhury NF, Arafat SY, Mullick MS. Depression, anxiety, stress among postgraduate medical residents: A cross sectional observation in Bangladesh. Iran J Psychiatry. 2019;14(3):192.

2. Dave S, Parikh M, Vankar G, Valipay SK. Depression, anxiety, and stress among resident doctors of a teaching hospital. Indian J Soc Psychiatry. 2018;34(2):163. DOI:10.4103/ ijsp.ijsp_72_17

3. Mousa OY, Dhamoon MS, Lander S, Dhamoon AS. The MD blues: under-recognized depression and anxiety in medical trainees. PloS one. 2016;11(6):e0156554. https://doi.org/ 10.1371/journal.pone.0156554 
Association of Different Levels of Anxiety in Resident Doctors with Factors related to the Postgraduate Training in Teaching Hospitals

4. Monrouxe LV, Bullock A, Tseng HM, Wells SE. Association of professional identity, gender, team understanding, anxiety and workplace learning alignment with burnout in junior doctors: a longitudinal cohort study. BMJ open. 2017;7(12). http://dx.doi.org/10.1136/bmjopen-2017-017942

5. Parr JM, Pinto N, Hanson M, Meehan A, Moore PT. Medical graduates, tertiary hospitals, and burnout: a longitudinal cohort study. Ochsner Journal. 2016;16(1):22-6.

6. Rana W, Mukhtar S, Mukhtar S. Mental health of medical workers in Pakistan during the pandemic COVID-19 outbreak. Asian J Psychiatr. 2020; 51:102080. https://dx.doi.org/ 10.1016\%2Fj.ajp.2020.102080

7. Rahman HA, Issa WB, Naing L. Psychometric properties of brief-COPE inventory among nurses. BMC Nurs. 2021;20(1):1-7. https://doi.org/10.1186/s12912-021-005925

8. McKinley N, McCain RS, Convie L, Clarke M, Dempster M, Campbell WJ, Kirk SJ. Resilience, burnout and coping mechanisms in UK doctors: a cross-sectional study. BMJ open. 2020;10(1). doi:10.1136/bmjopen-2019-031765

9. McCain RS, McKinley N, Dempster M, Campbell WJ, Kirk SJ. A study of the relationship between resilience, burnout and coping strategies in doctors. Postgrad. Med. J. 2018;94(1107):43-7. https://doi.org/10.1136/postgradmedj2016-134683

10. Khurshied S, Hisam A, Khurshid N, Khurshid M. Burnout among surgeons; depression, anxiety and stress between consultant versus post-graduate trainee. Pak J Med Sci. 2020; 36(7). https://doi.org/10.12669/pjms.36.7.1415

11. Scoppetta O, Cassiani-Miranda CA, Arocha-Díaz KN, Cabanzo-Arenas DF, Campo-Arias A. Validity of the patient health questionnaire-2 (PHQ-2) for the detection of depression in primary care in Colombia. J. Affect. Disord. 2021; 278:57682. https://doi.org/10.1016/j.jad.2020.09.096

12. Faiz S, Qureshi FM, Hussain AW, Nigah-e-Mumtaz S. Association of subjective memory complaints amid patients of Diabetes Mellitus Type II and Hypertension. Pak J Med Sci. 2021;37(2):477. https://dx.doi.org/ 10.12669\%2Fpjms. 37.2.3426

13. Bogue RJ, Downing NR. Research on physician burnout and wellbeing: a solution-oriented perspective. In Transforming the Heart of Practice 2019 (pp. 9-47). Springer, Cham. https://doi.org/10.1007/978-3-030-15250-5_2

14. Babore A, Lombardi L, Viceconti ML, Pignataro S, Marino V, Crudele M et.al. Psychological effects of the COVID-2019 pandemic: Perceived stress and coping strategies among healthcare professionals. Psychiatry research. 2020; 293:113366. https://doi.org/10.1016/j.psychres.2020.113366
15. Jalnapurkar I, Allen M, Pigott T. Sex differences in anxiety disorders: a review. J Psychiatry Depress Anxiety. 2018;4(12): 3-16. http://doi.org/10.24966/PDA-0150/100012

16. Hinz A, Klein AM, Brähler E, Glaesmer H, Luck T, RiedelHeller SG, Wirkner K, Hilbert A. Psychometric evaluation of the Generalized Anxiety Disorder Screener GAD-7, based on a large German general population sample. J. Affect. Disord. 2017; 210:338-44. https://doi.org/10.1016/j.jad.2016.12.012

17. Wahed WY, Hassan SK. Prevalence and associated factors of stress, anxiety and depression among medical Fayoum University students. Alexandria J. Med. 53(1):77-84. https://doi. org/10.1016/j.ajme.2016.01.005

18. Kousha M, Bagheri HA, Heydarzadeh A. Emotional intelligence and anxiety, stress, and depression in Iranian resident physicians. J Family Med Prim Care 2018;7(2):420424 https://dx.doi.org/10.4103\%2Fjfmpc.jfmpc_154_17

19. Bayram N, Bilgel N. The prevalence and sociodemographic correlations of depression, anxiety and stress among a group of university students". Soc Psychiat Epidemiol 2008;43 (8):667-72. https://doi.org/10.1007/s00127-008-0345-x

20. Fu W, Wang C, Zou L, Guo Y, Lu Z, Yan S, Mao J. Psychological health, sleep quality, and coping styles to stress facing the COVID-19 in Wuhan, China. Transl Psychiatry. 2020;10(1):1-9. https://doi.org/10.1038/s41398-020-00913-

21. Velten J, Bieda A, Scholten S, Wannemüller A, Margraf J. Lifestyle choices and mental health: a longitudinal survey with German and Chinese students. BMC Public Health. 2018;18(1):1-5 https://doi.org/10.1186/s12889-018-5526-2

22. Fan F, Zhang Y, Yang Y, Mo L, Liu X. Symptoms of posttraumatic stress disorder, depression, and anxiety among adolescents following the 2008 Wenchuan earthquake in China. J. Trauma Stress. 2011;24(1):44-53 https://doi.org/ 10.1002/jts.20599

23. Nasim S, Khan M, Aziz S. Impact of terrorism on health and Hospital Anxiety Depression Scale Screening in medical students, Karachi, Pakistan. JPMA. 2014;64(275):49

24. Flesia L, Monaro M, Mazza C, Fietta V, Colicino E, Segatto B, Roma P. Predicting Perceived Stress Related to the Covid19 Outbreak through Stable Psychological Traits and Machine Learning Models. J. Clin. Med. 2020;9(10):3350 https://doi.org/ $10.3390 / \mathrm{jcm} 9103350$ 